\title{
LITERATURA E DIÁSPORA: O CASO VLADIMIR NABOKOV
}

Denize Helena Lazarin*

(iD) https://orcid.org/0000-0001-6567-9083

Como citar este artigo: LAZARIN, D. H. Literatura e diáspora: o caso Vladimir Nabokov. Todas as Letras - Revista de Lingua e Literatura, São Paulo, v. 22, n. 3, p. 1-8, set./dez. 2020. DOI 10.5935/1980-6914/eLETLT2012100

Submissão: janeiro de 2019. Aceite: agosto de 2020.

Resumo: Nesta pesquisa pretendemos evidenciar de modo geral como a obra de Nabokov aborda a experiência do exílio. Sabemos que o próprio Nabokov fez parte da diáspora, tornando-se um white émigré ao sair da Rússia com a ascensão do regime socialista em 1917. Nossa hipótese é que a obra de Nabokov aborda a situação do white émigré de duas formas: de modo referencial no conjunto da obra e de forma alegórica em Lolita (1955). Enquanto referencial teórico, recorremos aos estudos de Brah (2002), Proffer (1994) e Said (2003).

Palavras-chave: Literatura. Nabokov. Obra. Diáspora. Exílio.

Para quem não tem mais pátria, é bem possível que o escrever se torne sua morada. (Theodor W. Adorno) 


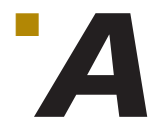

s palavras desta epígrafe lembram as de Humbert Humbert, narrador-protagonista de Lolita (1955), também "exilado" em uma prisão: "Ah, minha Lolita, tudo que me restou para brincar foram as palavras" (NABOKOV, 2003, p. 34)1. Elas bem mostram a ficcionalização da experiência diaspórica realizada por seu autor, que também fez da literatura seu refúgio. Entretanto, ao elencar os autores que abordam em sua obra a angústia experimentada pelo exilado, Said (2003, p. 49) acredita que "deve-se deixar de lado Joyce e Nabokov e pensar nas incontáveis massas para as quais foram criadas as agências da ONU". Pretendemos aqui justamente demonstrar o contrário, ou seja, por acreditarmos que a experiência diaspórica de Nabokov é emblemática das vivências de muitos exilados provenientes das massas refugiadas às quais Said se refere, nosso objetivo é mostrar que estas são contempladas em sua obra.

Vladimir Nabokov nasceu na Rússia Czarista em 1889, 28 anos antes da revolução que o obrigaria a deixar toda a sua vida para trás e tornar-se um white émigré, termo utilizado para designar os russos proveniente da diáspora que, como ele, foram despojados tanto de seus bens quanto da cidadania russa. Filho mais velho de Vladimir Dmitrievich Nabokov, advogado e influente politico russo, Nabokov teve, durante sua infância, uma primorosa instrução em inglês, francês e russo, além de todas as benesses destinadas à aristocracia russa pré-revolucionária. Apesar da situação confortável da família Nabokov, seu pai não só acreditava na necessidade de mudanças, como também lutava por elas, sendo membro do partido liberal Kadets. Entre 1904 e 1917, editou o jornal liberal Reich (O Discurso) e, ao assinar o Manifesto Vybog, o qual incitava a desobediência civil, foi condenado à prisão por alguns meses. Depois da Revolução de fevereiro de 1917, ele ajudou a elaborar o documento de recusa do grã-duque Michael Alexandrovich, herdeiro ao trono, sendo nomeado secretário do primeiro governo provisório. Contudo, depois da revolução, houve uma cisão entre seu partido, que desejava um governo liberal, e o partido de Lênin, os bolcheviques, que tomou o poder e instaurou o governo ditatorial.

Em 1917, a família Nabokov refugiou-se na Crimeia, onde Vladimir Dmitrievich Nabokov foi ministro da justiça. Dois anos depois, em 1919, a família se viu obrigada a deixar também a Crimeia em direção à Europa. Na Inglaterra, Nabokov estudou em Cambridge enquanto a família se estabeleceu na Alemanha, onde o pai fundou o periódico Rul (O Leme), no qual advogava por um governo democrático na Rússia. Em 1922, ao terminar seus estudos, Nabokov mudou-se para Berlim. Nesse mesmo ano, seu pai é assassinado por engano numa conferência política por um militante pró-monarquia.

De 1922 a 1937, Nabokov viveu na Alemanha, onde escrevia em russo para a comunidade émigré. Em 1925, casou-se com a judia Véra Slonim e, em 1934, nasceu seu único filho, Dmitri Nabokov. Contudo, em 1937, no auge do seu desenvolvimento artístico escrevendo em russo, ele se viu obrigado a emigrar novamente para manter sua esposa e seu filho a salvo dos nazistas.

Nos Estados Unidos, ele trabalhou no Museu de História Natural, na Wellesley College e na Universidade de Cornell, o que the garantiu maior tranquilidade financeira para dedicar-se à criação literária. O primeiro livro publicado em inglês

1 No original: "Oh, my Lolita, I have only words to play with!" (NABOKOV, 2000, p. 32). 
por Nabokov foi The real life of Sebastian Knight, em 1941, mas foi apenas a publicação de Lolita, em 1955, que lhe rendeu sucesso junto com o público. Atrelado à fama, veio o retorno financeiro, e Nabokov, sujeito diaspórico, fez sua última jornada em outubro de 1961, dessa vez para a Suiça, onde viveu até o fim de sua vida (1977) na impessoalidade de uma suite do Montreux Palace Hotel. Para Proffer (1994, p. 5),

[...] as imagens daquilo que o rodeava na infância tornam fácil de entender por que ele parecia recusar-se a construir um lar verdadeiro novamente, preferindo alojamentos temporários em apartamentos alugados, casas cujos proprietários estavam ausentes, e, finalmente, uma suite de hotel. Ele perdera um lar, uma terra e um mundo, e estava obviamente determinado a nunca tornar-se tão ligado a um lugar outra vez.

Da mesma forma que Humbert leva uma vida errante pelos hotéis de beira de estrada e atrações turísticas de cada cidadezinha durante sua "grande viagem pelos Estados Unidos", seu criador lembra, em sua autobiografia Speak, Memory (1967), que "o fato do sobrevivente mais insistente de [sua] herança russa ser uma valise de viagem é tão lógico quanto emblemático" (NABOKOV, 1968, p. 133). Nesse ponto, a alegoria pessoal de Lolita torna-se evidente, fazendo de Humbert Humbert um dublê de Nabokov Nabokov. Contudo, essa análise será desenvolvida mais adiante, sendo agora necessário conceituar o sujeito diaspórico: para Brah, o lar é um dos elementos fundamentais quando se trata de diáspora, pois não é possivel conceber dispersão sem a noção de centro. Para ela, "diáspora se refere a 'dispersão de'. Portanto, a palavra incorpora a noção de centro, local, um 'lar' a partir de onde a dispersão ocorre” (BRAH, 2002, p. 181, tradução nossa) ${ }^{2}$. O lar é um lugar mítico de desejo na imaginação diaspórica, o que também se nota no relato autobiográfico de Nabokov (1968, p. 233):

[...] mas mostre-me qualquer coisa em qualquer continente semelhante ao interior de S. Petersburgo e meu coração se derrete. O que seria de fato rever os meus primeiros recantos, dificilmente consigo imaginar. Algumas vezes, eu me imagino revistando-os com um passaporte falso, sob um nome suposto.

Por outro lado, o lar pode ainda relacionar-se à experiência vivida no dia a dia de uma comunidade, ou seja, os cheiros, os sons, as paisagens fazem com que o sujeito diaspórico passe a sentir como lar seu local de residência.

Entretanto, as relações de inclusão/exclusão operadas pelos indivíduos nativos podem influenciar tanto a relação de pertencimento quanto a formação da identidade dos sujeitos provenientes de grupos diaspóricos. Para Brah (2002, p. 183, tradução nossa), a identidade da comunidade diaspórica "[...] é constituído dentro do cadinho da materialidade cotidiana", ${ }^{3}$ na maneira como se inserem nos variados discursos, processos econômicos e politicos do Estado. O conceito de fronteira metafórica, conforme definido por Brah (2002, p. 198, tradução nossa), opera também nas relações de exclusão:

Fronteiras: linhas divisórias arbitrárias que são simultaneamente sociais, culturais e psíquicas; territórios a serem patrulhados contra aqueles que são conside-

\footnotetext{
No original: "diaspora refers to a 'dispersion from'. Hence the word embodies a notion of a centre, a locus, a 'home' from where the dispersion occurs".

3 No original: "is constituted within the crucible of the materiality of everyday life".
} 
rados como outsides, aliens, os Outros; formas de demarcação onde o próprio ato de proibição inscreve a transgressão; zonas onde o medo do Outro é o medo do eu; lugares onde as reivindicações de propriedade-afirmam "meu", "seu" e “deles" - são vigiadas, contestadas, defendidas e disputadas ${ }^{4}$.

Ou seja, além de uma divisão geográfica, onde ao indivíduo pode ser negada a entrada, existe uma fronteira metafórica, isto é, uma demarcação psíquica e cultural que a todo momento monitora o indivíduo. Essa demarcação invisível pode ocorrer oficialmente quando, por exemplo, um indivíduo é considerado "suspeito" por seu biótipo. Ou ainda informalmente: todo momento em que o imigrante é questionado a respeito de sua procedência, a fronteira metafórica se opera sobre ele lembrando-o de seu status de alteridade. Durante os anos passados na Inglaterra, Nabokov (1968, p. 249) assimilou seu status de Outro: "eu pensaria em mim mesmo como um ser exótico e fabuloso num disfarce de jogador inglês, compondo versos numa língua que ninguém entendia sobre um país remoto que ninguém conhecia".

Para Brah (2002, p. 199, tradução nossa), existe uma rede organizada de controle e exclusão do imigrante, cujos mecanismos são: "dificuldades de obter vistos, confrontar os controles de imigração, detenções e deportações, e até mesmo encarar a possibilidade em algumas circunstâncias de perder a vida" 5 . Essas situações eram comuns aos white émigrés. Em seu relato autobiográfico, Nabokov define a tentativa de renovação de vistos de permanência como um cerco que se fechava sobre o requerente por meio da burocracia. Ele ainda descreve a dificuldade em conseguir um visto de entrada:

A Liga das Nações equipou os émigrés que haviam perdido sua cidadania russa com um assim chamado passaporte "Nansen", um documento bastante inferior, de um verde doentio. Seu portador era um pouco melhor do que um criminoso em livramento condicional e tinha de passar pelas provações mais horríveis a cada vez que quisesse viajar de um país a outro, e quanto menor o país maior o estardalhaço que faziam (NABOKOV, 1968, p. 256).

A situação do white émigré tinha suas especificidades, pois deixar a Rússia de Lênin e Stalin significou perder a possibilidade de retorno, o que colocou os exilados - entre eles, poetas, romancistas, críticos, historiadores e filósofos - numa situação de errância constante pelas nações europeias. Nabokov acreditava que um expatriado era visto pelo europeu tal como uma criança concebida fora do casamento é vista por um religioso.

A maioria dos imigrantes russos teve que mudar de profissão, de modo geral adotando ocupações inferiores ao seu grau de instrução, a fim de obter a sobrevivência, tornando-se o que Brah (2002, p. 199) define como trabalhadores periféricos de baixa remuneração. O próprio Nabokov deu aulas de tênis, de língua inglesa e fazia traduções e leituras públicas de suas obras, enquanto outros escritores mais velhos, que não apresentavam essa mobilidade, ficavam sujeitos a receber auxílios (NABOKOV, 1968).

\footnotetext{
4 No original: "Borders: arbitrary dividing lines that are simultaneously social, cultural and psychic; territories to be patrolled against those whom they construct as outsides, aliens, the Others; forms of demarcation where the very act of prohibition inscribes transgression; zones where fear of the Other is the fear of the self; places where claims to ownership - claims to 'mine', 'yours' and 'theirs' - are staked out, contested, defended, and fought over".

5 No original: "difficulties of gaining visas, confronting immigration checks, detentions and deportations, and even facing the possibility in some circumstances of losing one's life".
} 
Essa situação de exclusão experimentada na Europa é o que movia o white émigré a se juntar em comunidades, editar jornais e promover conferências para discutir a situação de seu país natal acalentando a possibilidade de regresso. Mas, qual era o posicionamento de Nabokov? Segundo Proffer (1994, p. 5), Nabokov adotara uma posição estranha a qualquer classificação: "nunca foi um membro voluntário de um clube, e, na verdade, nos arquivos havia poucas fotos de Nabokov com outros escritores". Diferentemente de seu pai, ele não fundou jornal nem escrevia artigos discutindo questões politicas, tampouco suas obras apresentavam temáticas engajadas em questões sociais. Esse posicionamento pode ser compreendido por meio de sua biografia: ele crescera com o pai se envolvendo em movimentos sociais e isso lhe era desconfortável, pois fora motivo de chacotas por parte de outros colegas (NABOKOV, 1968). Assim, desde cedo, conheceu o alto preço do discurso, pois, naqueles tempos, o falar poderia materializar-se numa passagem de ida à Sibéria. Ou igualmente aos campos de concentração de Hitler, como ocorrera com seu irmão Sergey, que em 1945 morrera de inanição num campo de concentração. Ele fora mandado para lá por criticar abertamente o regime do governo alemão, sendo assim considerado um espião britânico.

Contudo, o fato de Nabokov não se posicionar abertamente e não se engajar politicamente não significava que ele não amava sua pátria natal. Ele amava a Rússia e, como citado acima, desejava vê-la novamente. Entretanto, aquela Rússia de sua infância - seu objeto de desejo - já não existia mais, mas estava eternamente cristalizada em sua memória afetiva. E este é o ponto principal em que Nabokov se diferenciava de muitos white émigrés: ele era consciente de que não conseguiria tê-la de volta; sendo assim, o mais próximo que poderia chegar dela seria por meio de recriações ficcionais.

Diante da impossibilidade de retorno, as recriações literárias são abundantes no decorrer de sua obra e vão desde o assassinato de John Shade em Pale fire (1962), que se dá por engano, como ocorre com o pai de Nabokov em 1922, passando pelo passaporte "Nansen" de Valéria em Lolita, até a inserção de white émigrés como personagens em suas obras. Entretanto, poderiamos afirmar que é em Ada or Ardor: a family chronicle (1969) que Nabokov atinge seu ápice nesse quesito. Nessa obra, ele cria um universo maravilhoso, ou seja, o planeta Antiterra, que se caracteriza por uma peculiar mistura entre Rússia e América. A família russa de tradicionais colonizadores de um país de dimensões continentais, que em muito se assemelha à América, desfruta de uma vida aristocrática em Ardis, sua suntuosa residência de campo, tal como a família Nabokov em Vyra. E as relações não param por aí: o protagonista Van Veen conta sua história nos moldes em que Nabokov o faz em Speak, Memory; Ada, como seu autor, coleciona borboletas; e como no lar de Nabokov, as linguas faladas em seu mundo ficcional são o russo, o inglês e o francês.

Entretanto, as recriações ficcionais de Nabokov não apenas representam a pátria natal da infância, mas também a própria condição diaspórica. É o caso de Humbert Humbert, narrador-protagonista de Lolita, que chega aos Estados Unidos durante a Segunda Guerra Mundial. Antes disso, porém, o francês Humbert se enreda numa paródia de triângulo amoroso envolvendo sua esposa e um white émigré (o ex-coronel do Exército Branco czarista Maximovitch), sobre o qual faz comentários jocosos, explorando a situação marginal desses imigrantes.

Contudo, ao chegar aos Estados Unidos, é Humbert quem se encontra na situação de imigrante. Na verdade, Nabokov parece representar a típica situação 
do imigrante que desembarca num novo mundo, desconhecido e, talvez por isso, desconfortável. O desconforto provém do choque cultural que, muitas vezes, se resolve pela crítica do outro por meio da reafirmação da própria cultura, ainda mais quando essa cultura the parece "superior". Said (2005, p. 62) nos oferece alguns exemplos em Representações do intelectual (1994), sendo o caso de Theodor Adorno o mais emblemático:

Adorno era completamente europeu, um homem formado por inteiro na mais elevada cultura europeia [...] o tempo que viveu na América marcou-o para sempre com os traços do exílio. Detestava jazz e tudo relacionado a cultura popular, não tinha nenhuma afeição a paisagem, parece ter se comportado deliberadamente como um mandarim no trato com os outros. Por isso, e também por ter sido formado numa tradição filosófica marxista-hegeliana, tudo o que fosse relacionado a influência mundial norte-americana nos filmes, na indústria, nos hábitos cotidianos, na aprendizagem baseada em fatos e no pragmatismo deixava-o enfurecido.

Não era diferente a postura de Humbert, que constantemente zombava da cultura burguesa norte-americana. É o que ele faz quando Charlotte, sua esposa, o informa sobre uma viagem a dois programada por ela, respondendo da seguinte maneira:

Posso imaginar como você, uma saudável moça americana, ficaria feliz em cruzar o Atlântico no mesmo navio em que estivesse viajando a lady Bumble - ou San Bumble, o Rei da Carne Congelada, ou alguma vagabunda de Hollywood. E não duvido que você e eu poderíamos aparecer num belo anúncio de qualquer agência de viagens se nos fotografassem contemplando - você, com os olhos cintilantes de excitação, eu reprimindo minha inveja e admiração - os Sentinelas do Palácio, ou os Guardas Escarlates, ou os Comedores de Castores, ou o que quer que se chamem (NABOKOV, 2003, p. 92) ${ }^{6}$.

Apesar de Jameson (2005, p. 234) interpretar Lolita como uma alegoria nacional a uma América adolescente, impudica e vulgar - em oposição à Europa cansada e exageradamente culta -, é possível também interpretar o romance como uma alegoria pessoal, uma forma criptografada do exílio permanente vivenciado pelo autor.

As evidências até então apresentadas em Lolita não englobam o que chamamos de alegoria pessoal, pois são por demais referenciais. Na verdade, a alegoria do exílio transparece justamente na condição central do narrador-protagonista: a pedofilia. Mas qual é a relação entre pedofilia e exílio? Para Santiago (2006, p. 348), "o pedófilo é aquele que não esquece a própria infância, que dela não se liberta”. Do mesmo modo, o exilado é aquele que não esquece a pátria natal, que de suas lembranças também não se liberta. Ou seja, o Humbert perdido em sua infância é uma alegoria do Nabokov perdido em suas lembranças.

Ainda na primeira página de Lolita, Humbert indica a razão de sua pedofilia: "Na verdade, talvez jamais tivesse existido uma Lolita se, em certo verão, eu não

6 Tradução de Jorio Dauster do original: "I can well imagine the thrill that you, a healthy American gal, must experience at crossing the Atlantic on the same ocean liner with Lady Bumble - or Sam Bumble, the Frozen Meat King, or a Hollywood harlot. And I doubt not that you and I would make a pretty ad for the Traveling Agency when portrayed looking - you, frankly starry-eyed, I, controlling my envious admiration - at the Palace Sentries, or Scarlet Guards, or Beaver Eaters, or whatever they are called" (NABOKOV, 2000, p. 90). 
houvesse amado uma menina primordial" (NABOKOV, 2003, p. 11) ${ }^{7}$. A garota primordial que, segundo ele, o aprisionou em sua infância é Annabel Leigh, a adolescente por quem se apaixonara num verão praiano na Riviera. A interrupção do ato sexual entre ambos teria sido a razão de sua busca constante por ninfetas, pois somente a relação sexual com uma adolescente poderia proporcionar-lhe o prazer que fora interrompido anos antes em seu encontro sexual com Annabel. E desse modo ele segue ao longo de toda a sua vida, buscando em cada nova ninfeta a encarnação da ninfeta primordial, até que ela se materializa em Lolita, conforme ele afirma mais adiante na narrativa:

O competente psiquiatra que estuda meu caso - e que, segundo imagino, já está a essa altura tão fascinado pelo dr. Humbert quanto um pobre coelho diante de uma serpente - deve sentir-se ansioso para que eu vá com minha Lolita para alguma praia e lá obtenha, finalmente, a "gratificação" do desejo de toda a vida, libertando-me assim da obsessão "subconsciente" de um romance frustrado com a menina primordial, a pequena mademoiselle Lee (NABOKOV, 2003, p. 169) ${ }^{8}$.

Curiosamente, Nabokov (1968, p. 139) também se apaixonara por uma garota durante suas férias com a família numa praia europeia: "Durante os dois meses de nossa estada em Biarritz minha paixão por Colette a tudo ultrapassou, menos minha paixão por Cleópatra". Outra peculiaridade é a paródia que Nabokov faz ao modificar a grafia do sobrenome de Annabel, passando de Leigh para Lee. Essa modificação gráfica, que em nada altera a sonoridade, faz referência ao poema Annabel Lee, de Edgar Allan Poe, escritor que, segundo Humbert, também era um apreciador de ninfetas. Esse poema de Poe tematiza o amor juvenil entre adolescentes que se conheceram em situação semelhante à que Humbert conhece sua Annabel e à que Nabokov conheceu sua Colette.

\section{CONSIDERAÇões FINAIS}

Ao longo dos anos, a crítica de Nabokov vem se debruçando maciçamente sobre os aspectos formais de sua obra. Que o autor é um mestre na lapidação do texto é ponto passivo, e esse foi o fator preponderante para a liberação de Lolita em países com programas de censura - como foi o caso do Brasil -, pois, apesar da temática que "agride a moral e os bons costumes", é impossivel negar seu valor literário levando-se em conta padrões formalistas de avaliação. Por outro lado, a postura política de Nabokov, no que se refere à sua condição de exilado, foi por muitos anos alvo de criticas. Conforme Said (2005), cabe ao intelectual exilado uma postura de inquietação e de crítica. Contudo, a obra de Nabokov não tem sido analisada por esse prisma, de modo que este nunca foi considerado um autor engajado.

Conforme abordamos neste artigo, apesar de a obra de Nabokov não ter tematizado diretamente a condição diaspórica do white émigré, com vistas à crítica

7 Tradução de Jorio Dauster do original: "In point of fact, there might have been no Lolita at all had I not loved, one summer, a certain initial girl-child" (NABOKOV, 2000, p. 9).

8 Tradução de Jorio Dauster do original: "The able psychiatrist who studies my case - and whom by now Dr. Humbert has plunged, I trust, into a state of leporine fascination - is no doubt anxious to have me take my Lolita to the seaside and have me find there, at last, the 'gratification' of a lifetime urge, and release from the 'subconscious' obsession of an incomplete childhood romance with the initial little Miss Lee" (NABOKOV, 2000, p. 166-167). 
do governo russo que os tornou exilados, ela abordou de modo abrangente e de forma referencial essas questões. Não obstante, temos ainda em Lolita uma elaboração alegórica da condição diaspórica de Nabokov, de modo que, se por um lado não é possível elencá-lo entre os que chamamos de autores engajados, também não podemos concordar com Said (2003) em excluir sua literatura da chamada "literatura de exílio", que apresenta as angústias dessa condição.

\section{LITERATURE AND DIASPORA: VLADIMIR NABOKOV's CASE}

Abstract: In this research we intend to show in general how the work of Nabokov approaches the experience of exile. We know that Nabokov himself was part of the diaspora, becoming a white émigré when he left Russia with the rise of the socialist government in 1917. Our hypothesis is that Nabokov's work addresses the situation of white émigré in two ways: in a referential mode in the whole work and allegorically in Lolita (1955). As a theoretical reference, we based on the studies of Brah (2002), Proffer (1994), and Said (2003).

Keywords: Literature. Nabokov. Works. Diaspora. Exile.

\section{REFERÊNCIAS}

BRAH, A. Cartoraphies of diáspora: contesting identities. London: Rotledge, 2002. JAMESON, F. Modernidade singular. Tradução Roberto Franco Valente. Rio de Janeiro: Civilização Brasileira, 2005.

NABOKOV, V. A verdadeira vida de Sebastian Knight. Tradução José Rubens Siqueira. Rio de Janeiro: Alfaguara, 2010.

NABOKOV, V. Ada ou Ardor: crônica de uma família. Tradução Jorio Dauster. São Paulo: Companhia das Letras, 2005.

NABOKOV, V. Fala, memória. Tradução Luiz Carlos Dolabela Chagas. Rio de Janeiro: Editora Saga, 1968.

NABOKOV, V. Fogo pálido. Tradução Jorio Dauster e Sérgio Duarte. São Paulo: Círculo do Livro, 1990.

NABOKOV, V. The Annotated Lolita. London: Penguin Books, 2000.

NABOKOV, V. Lolita. Tradução Jorio Dauster. São Paulo: Companhia das Letras, 2003.

PROFFER, E. (org.). Vladimir Nabokov: uma fotobiografia. Tradução Terezinha Barretti Mascarenhas. São Paulo: Ars Poetica, 1994.

SAID, E. Reflexões sobre o exílio. In: SAID, E. Reflexões sobre o exílio e outros ensaios. Tradução Pedro Maia Soares. São Paulo: Companhia das Letras, 2003. SAID, E. Representações do intelectual: as Conferências Reith de 1993. Tradução Milton Hatoum. São Paulo: Companhia das Letras, 2005.

SANTIAGO, S. Lolita \& outras ninfetas. In: SANTIAGO, S. Ora (direis) puxar conversa!: ensaios literários. Belo Horizonte: Editora UFMG, 2006. 